Pacific Journal of Mathematics

SUFFICIENT CONDITIONS FOR THE SET OF HAUSDORF
COMPACTIFICATIONS TO BE A LATTICE 


\title{
SUFFICIENT CONDITIONS FOR THE SET OF HAUSDORFF COMPACTIFICATIONS TO BE A LATTICE
}

Fu-Chien Tzung

\begin{abstract}
Let $K(X)$ be the complete upper semilattice of compactifications of a completely regular Hausdorff space $X$. We show that if $\beta X \backslash X$ is $C^{*}$-embedded in $\beta X$ and if either $\alpha X \backslash X$ is realcompact or is a $P$-space for some $\alpha X$ in $K(X)$, then $K(X)$ is a lattice.
\end{abstract}

1. Introduction. Throughout this paper, all topological spaces under consideration are supposed to be completely regular and Hausdorff, unless stated otherwise.

A compactification of a space $X$ is a compact space $\alpha X$ which contains $X$ as a dense subspace. We say $\alpha_{1} X$ and $\alpha_{2} X$ are equivalent compactifications of $X$ if there is a homeomorphism $h$ from $\alpha_{1} X$ onto $\alpha_{2} X$ such that $h$ restricted to $X$ in $\alpha_{1} X$ is the identity map onto $X$ in $\alpha_{2} X$. We do not distinguish between equivalent compactifications. For compactifications $\alpha_{1} X$ and $\alpha_{2} X$, we say that $\alpha_{1} X \geqq \alpha_{2} X$ if and only if there is continuous function from $\alpha_{1} X$ onto $\alpha_{2} X$ such that $h$ restricted to $X$ is the identity. Thus, $\alpha_{1} X$ is equivalent to $\alpha_{2} X$ if and only if $\alpha_{1} X \geqq \alpha_{2} X$ and $\alpha_{2} X \geqq \alpha_{1} X$. Let $K(X)$ denote the set of all compactifications of $X$. Then $K(X)$ with the order $\geqq$ defined as above is a complete upper semilattice. Lubben [3] proved that $X$ is locally compact if and only if $K(X)$ is a complete lattice. Next, Shirota [6] showed that if $X$ is first countable then $K(X)$ is a lattice if and only if $X$ is locally compact. Thus, $Q$ (=rationals) provides us with the simplest example for which $K(Q)$ is not a lattice. Visliseni and Flaksmaier [9] showed that if there exists a sequence in $\beta X \backslash X$ which converges to a point in $X$, then $K(X)$ cannot be a lattice. In the same paper they also constructed a nonlocally compact space $X$ for which $K(X)$ is a lattice.

In this paper we determine two classes of spaces which properly contain the class of locally compact spaces and for which $K(X)$ is a lattice, whenever $X$ is a member of either of them. Examples are constructed to show that none of these conditions are necessary.

2. Preliminaries. The terminology of [1] and [11] are used throughout. The following will be needed for subsequent development. 
Definition 2.1. Let $\alpha X \in K(X), f_{\alpha}: \beta X \rightarrow \alpha X$ be continuous and $\left.f_{\alpha}\right|_{X}=\mathrm{id}$. Then $f_{\alpha}$ is closed and hence we can consider $\alpha X$ as the quotient space of $\beta X$ induced by $f_{\alpha}$. Define

$$
\mathscr{F}(\alpha X)=\left\{f_{\alpha}^{-1}(p) \mid p \in \alpha X \backslash X\right\} \text {. }
$$

THeOrem 2.2 (Magill [4]). Let $\alpha_{1} X, \alpha_{2} X \in K(X)$. Then $\alpha_{1}^{\prime} X \leqq \alpha_{2} X$ if and only if each set in $\mathscr{F}\left(\alpha_{2} X\right)$ is a subset of a set in $\mathscr{F}\left(\alpha_{1} X\right)$.

Definition 2.3. A space $X$ is said to be of countable type if and only if every compact subset is contained in a compact set of countable character (i.e., one having a countable neighborhood system).

TheOREm 2.4 ([2], page 115). A space $X$ is of countable type if and only if $\beta X \backslash X$ is Lindelöf.

THEOREM 2.5 ([1], page 115). Lindelöf spaces are realcompact.

Definition 2.6. A space $X$ is of point countable type if and only if every point is contained in a compact set of countable character.

THeOREM 2.7 ([8], page 341). If $X$ is a space of point countable type then $\beta X \backslash X$ is realcompact.

TheOREM 2.8 ([9], page 1424). If, in the subspace $\beta X \backslash X$ of the space $\beta X$, there exists a countable sequence of points converging to some point in $X$, then $K(X)$ is not a lattice.

\section{Major results.}

Lemma 3.1 ([10], page 28). $\beta X \backslash X$ is $C^{*}$-embedded in $\beta X$ if and only if $\mathscr{C} l_{\beta X}(\beta X \backslash X)=\beta(\beta X \backslash X)$.

Definition 3.2. For $\alpha X \in K(X)$, let $f_{\alpha}: \beta X \rightarrow \alpha X$ be the quotient map, define

$$
\mathscr{C l}_{\alpha}=\left\{p \in \beta X|X|\left|f_{\alpha}^{-1}\left(f_{\alpha}(p)\right)\right|>1\right\}
$$

and

$$
\mathscr{E}_{\alpha}=\left\{F \leqq \mathscr{C}_{\alpha} \mid F=f_{\alpha}^{-1}(y) \text {, some } y \in \alpha X\right\} \text {. }
$$

Lemma 3.3. If $\mathscr{C} l_{\beta, X}\left(\mathscr{C l}_{\alpha}\right) \subseteq \beta X \backslash X$ for every $\alpha X \in K(X)$, then $K(X)$ is a lattice. 
Proof. Since $K(X)$ is a complete upper semi-lattice, it is sufficient to show any two elements of $K(X)$ have a lower bound. Let $\alpha_{1} X, \alpha_{2} X \in K(X) . \quad A=\mathscr{C} l_{\beta X}\left(\mathscr{C}_{\alpha_{1}}\right) \cup \mathscr{C} l_{\beta X}\left(\mathscr{C}_{\alpha_{2}}\right)$ is compact in $\beta X \backslash X$. Obtain $\alpha X$ by identifying $A$ to a point, then $\alpha X$ is a compactification of $X$. Clearly, each set in $\mathscr{F}\left(\alpha_{i} X\right)$ is a subset of a set in $\mathscr{F}(\alpha X)$ for $i=1,2$. By Theorem 2.2, $\alpha X \leqq \alpha_{1} X, \alpha_{2} X$. Hence, $K(X)$ is a lattice.

LEMma 3.4 ([1], page 62). Let $f: X \rightarrow Y$ be continuous, $A$ be dense in $X$. If $\left.f\right|_{A}$ is a homeomorphism, then $f(X \backslash A) \subseteq Y \backslash f(A)$.

DeFinition 3.5. Let $Y$ be a quotient space of $X$ with the quotient map $P$. Let $\left\{A_{i}\right\}_{i=1}^{k}$ be a collection of disjoint, nonempty subsets in $X$ with $k \geqq 2$. We say $\left\{A_{i}\right\}_{i=1}^{k}$ is a section partition induced by $P$ if and only if there exists $B \subseteq Y$ such that $P\left(A_{i}\right)=B$ and $P^{-1}(b) \cap A_{i}$ is a singleton for $1 \leqq i \leqq k, b \in B . \quad P$ induces a partition on $A=\bigcup_{i=1}^{k} A_{i}$; namely, $A=\bigcup_{b_{\in} B} A_{b}, A_{b_{1}} \cap A_{b_{2}}=\dot{\phi}$ if $b_{1} \neq b_{2}$, where $A_{b}=\bigcup_{i=1}^{k}\left(P^{-1}(b) \cap A_{i}\right)$. This partition induces the section correspondence induced by $P$ on $A$.

LEMMA 3.6. If $\beta X \backslash X$ is $C^{*}$-embedded in $\beta X$ then for every $\alpha X \in K(X)$, $\mathscr{C l}_{\alpha}$ contains no copy of $N$ which is C-embedded in $\beta X \backslash X$.

Proof. Let $\alpha X \in K(X)$ such that $\mathscr{K}_{\alpha}$ contains a copy of $N$ which is $C$-embedded in $\beta X \backslash X . \quad F$ is compact for each $F \in \mathscr{E}_{\alpha}$, so it can contain only finitely many points of $N$. Form $A$ by choosing one point from each nonempty $F \cap N$, then $A$ is infinite. Let $h \in C(\beta X \backslash X)$ such that $h(A)=\boldsymbol{N} \subseteq \boldsymbol{R}$. $\left.\quad h\right|_{A}$ carries $A$ homeomorphically onto a closed set in $R$, so $A$ is $C$-embedded in $\beta X \backslash X$ by 1.19 of [1]. Therefore, $A$ is a copy of $N$, which is $C$-embedded in $\beta X \backslash X$. If $F=$ $f_{\alpha}^{-1}\left(f_{\alpha}(a)\right)$ for some $a \in A$ then since $a \in \mathscr{C}_{\alpha}$, we have $F \in \mathscr{C}_{\alpha}$. Let $\mathscr{A}=\left\{F \in \mathscr{E}_{\alpha} \mid F \cap A \neq \phi\right\}$. Form $B$ by choosing one point from each $F \backslash A, F \in \mathscr{A}$. $\{A, B\}$ is a section partition induced by $f_{\alpha}$. We want to show that $B$ is closed in $\beta X \backslash X$. Let $\left(b_{\lambda}\right)$ be an ultranet in $B$, and $b_{\lambda} \rightarrow b \in(\beta X \backslash X) \backslash B$. Let $\left(a_{\lambda}\right)$ be the corresponding ultranet in $A$ through the section correspondence induced by $f_{\alpha}$ on $f_{\alpha}(A)$. Since $\beta X$ is compact, $a_{\lambda} \rightarrow a \in \beta X$. Clearly, $\left(a_{\lambda}\right)$ is nontrivial, since $\left(b_{\lambda}\right)$ is nontrivial. Also, $a \in X$, since $A$ is closed and discrete in $\beta X \backslash X$. It is known that $f_{\alpha}$ is continuous, so $f_{\alpha}\left(a_{\lambda}\right) \rightarrow f_{\alpha}(a)$ and $f_{\alpha}\left(b_{\lambda}\right) \rightarrow f_{\alpha}(b)$. Since $f_{\alpha}\left(a_{\lambda}\right)=f_{\alpha}\left(b_{\lambda}\right)$ for all $\lambda$, and the limit points of these nets are unique, it follows that $f_{\alpha}(a)=f_{\alpha}(b)$. This is not possible since $f_{\alpha}(\beta X \backslash X) \subseteq \alpha X \backslash f_{\alpha}(X)$ by Lemma 3.4. Thus $B$ is closed in $\beta X \backslash X$. Since $A$ is a $C$-embedded copy of $N$ and $B$ is a closed set disjoint 
from $A$, so $A$ and $B$ are completely separated in $\beta X \backslash X$ by $3 B$ of [1]. As $\beta X \backslash X$ is $C^{*}$-embedded in $\beta X$, therefore $A$ and $B$ are completely separated in $\beta X$ by 1.17 of [1]. It follows that $\mathscr{C l}_{\beta X}(A) \cap$ $\mathscr{C} l_{\beta X}(B)=\phi$. Choose $\left(a_{\lambda}\right)$ in $A$ and $\left(b_{\lambda}\right)$ in $B$ as before, with $a \lambda \rightarrow a \in X$, $b_{\lambda} \rightarrow b \in X$. Then $f_{\alpha}(a)=f_{\alpha}(b)$. This is a contradiction, since $\left.f_{\alpha}\right|_{X}$ is one-to-one. Hence $\mathscr{K}_{\alpha}$ contains no copy of $N$, which is $C$-embedded in $\beta X \backslash X$ for all $\alpha X$ in $K(X)$.

THEOREM 3.7. If $\beta X \backslash X$ is $C^{*}$-embedded in $\beta X$, and if $\alpha X \backslash X$ is realcompact for some $\alpha X$ in $K(X)$ then $K(X)$ is a lattice.

Proof. If $\alpha X \backslash X$ is realcompact for some $\alpha X$, then $\beta X \backslash X$ is realcompact by 8.13 of [1].

Claim. $\mathscr{C} l_{\beta X}\left(\mathscr{l}_{\alpha}\right) \subseteq \beta X \backslash X$ for every $\alpha X \in K(X)$. Suppose not, then there exists $\alpha X \in K(X)$ such that $\mathscr{C l}_{\alpha}$ has a limit point $x_{0} \in X$. Let $Y=\left\{x_{0}\right\} \cup(\beta X \backslash X)$ endowed with the relative topology as a subspace of $\beta X . \quad \beta X \backslash X$ is realcompact and dense in $Y$, so $\beta X \backslash X$ is not $C$-embedded in $Y$. Let $f \in C(\beta X \backslash X)$ such that $f$ cannot be extended to $Y$. Let $[-\infty, \infty]$ be the two-point compactification of $\boldsymbol{R}$. Clearly, $f$ can be considered as a continuous function of $\beta X \backslash X$ into $[-\infty, \infty]$. $f$ has an extension $\bar{f}$ from $\beta(\beta X \backslash X)=\mathscr{C}_{\beta X}(\beta X \backslash X)$ into $[-\infty, \infty]$. Without loss of generality, we may assume $\bar{f}\left(x_{0}\right)=\infty$. Since $x_{0} \in$ $C l_{\beta X \mid X}\left(\mathscr{C}_{\alpha}\right)$, so $f$ is unbounded on $\mathscr{C}_{\alpha}$. By 1.20 of [1], $\mathscr{C}_{\alpha}$ contains a copy of $N$ which is $C$-embedded in $\beta X \backslash X$. This contradicts Lemma 3.6, and hence $C l_{\beta X}\left(\mathscr{C}_{\alpha}\right) \subseteq \beta X \backslash X$ for every $\alpha X \in K(X)$. Lemma 3.3 shows that $K(X)$ is a lattice.

CoRollary 3.8. If $X$ is a space of point countable type and $\beta X \backslash X$ is $C^{*}$-embedded in $\beta X$ then $K(X)$ is a lattice.

Theorem 3.9. ${ }^{1}$ If $\beta X \backslash X$ is $C^{*}$-embedded in $\beta X$ and if $\alpha X \backslash X$ is a P-space for some $\alpha X \in K(X)$, then $K(X)$ is a lattice.

Proof. We claim that $f_{\alpha}\left(\mathscr{C}_{\alpha}\right)$ is finite. For if $f_{\alpha}\left(\mathscr{C}_{\alpha}\right)$ is infinite then it contains a countably infinite subset $A$. By $4 K$ of [1], we see that $A$ is a copy of $N$, which is $C$-embedded in $\alpha X \backslash X$. Let $f \in C(\alpha X \backslash X)$ such that $f(A)=N \leqq R$. Hence, $f \circ f_{\alpha} \in(\beta X \backslash X)$ is unbounded on $f_{\alpha}^{-1}(A) \subseteq \mathscr{A}_{\alpha}$. Thus $f_{\alpha}^{-1}(A)$ contains a copy of $N$ which is $C$-embedded in $\beta X \backslash X$. Since $\beta X / X$ is $C^{*}$-embedded in $\beta X$, this contradicts Lemma 3.6. Therefore, $f_{\alpha}\left(\mathscr{N}_{\alpha}\right)$ is finite. Let $\gamma X \in K(X)$.

${ }^{1}$ Yusuf Unlü proved independently in his doctoral thesis [7] that $K(X)$ is a lattice if either (1) $\beta X \backslash X$ is realcompact and $C^{*}$-embedded in $\beta X$, or (2) $\beta X \backslash X$ is a $P$-space and $\mathscr{C} l_{\beta X}(\beta X \backslash X)$ is an $F$-space. 
Claim. $f_{\alpha}\left(\mathscr{C l}_{\gamma} \mid \mathscr{C}_{\alpha}\right)$ is finite. Suppose $f_{\alpha}\left(\mathscr{C l}_{\gamma} \mid \mathscr{C}_{\alpha}\right)$ is infinite then $\mathscr{C} \mathscr{C}_{\gamma} \mathscr{C}_{\alpha}$ contains a copy of $N$ which is $C$-embedded in $\beta X \backslash X$. This is a contradiction. $\mathscr{C}_{\alpha}=U\left\{f_{\alpha}^{-1}(p) \mid p \in f_{\alpha}\left(\mathscr{C}_{\alpha}\right)\right\}$ so that $\mathscr{C}_{\alpha}$ is a finite union of closed (hence compact) subsets of $\beta X$. Thus $\mathscr{A}_{\alpha}$ is compact. Similarly, $\mathscr{L}_{\gamma} \subseteq U\left\{f_{\alpha}^{-1}(p) \mid p \in f_{\alpha}\left(\mathscr{L}_{Y} \mid \mathscr{L}_{\alpha}\right)\right\} \cup \mathscr{A}_{\alpha}$ and both of these sets are compact. Therefore, $C l_{\beta X}\left(\mathscr{C l}_{\gamma}\right) \subseteq \beta X \backslash X$. Since this is for an arbitrary $\gamma X \in K(X)$, the theorem follows from Lemma 3.3.

We summarize the major results of this section in the following theorem:

TheOREM 3.10. If $\beta X \backslash X$ is $C^{*}$-embedded in $\beta X$ then any of the following conditions implies that $K(X)$ is a lattice:

(i ) $\alpha X \backslash X$ is realcompact for some $\alpha X \in K(X)$,

(ii) $\alpha X \backslash X$ is a P-space for some $\alpha X \in K(X)$,

(iii) $X$ is of countable type,

(iv) $X$ is of point-countable type.

Note that the class of spaces $X$ for which $\beta X \backslash X$ is $C^{*}$-embedded in $\beta X$ and for which $\alpha X \backslash X$ is realcompact for some $\alpha X$ in $K(X)$ contains the class of locally compact spaces. $(\beta X \backslash X$ is compact so that it is both realcompact and $C^{*}$-embedded in $\beta X$.) Likewise, the class of spaces $X$ for which $\beta X \backslash X$ is $C^{*}$-embedded in $\beta X$ and for which $\alpha X \backslash X$ is a $P$-space for some $\alpha X$ in $K(X)$ contains the class of locally compact spaces. ( $\beta X \backslash X$ is $C^{*}$-embedded in $\beta X$ since it is compact and $\omega X \backslash X=\{p\}$ is a $P$-space.) Thus our results here can be considered as generalizations of those of Lubben [3].

4. Examples. Let $\Omega$ denote the class of ordinals. For $\alpha \in \Omega$, $W(\alpha)=\{\alpha \in \Omega \mid \sigma<\alpha\} . \quad \omega$ will denote the smallest member of $\Omega$ with infinitely many predecessors: $W(\omega)$ is infinite and for all $\alpha<\omega$, $W(\alpha)$ is finite. $\omega_{1}$ will denote the smallest member of $\Omega$ with uncountably many predecessors.

THeOREM 4.1 ([1], page 138). If $X$ is compact, with $|X|<\aleph_{\alpha}$, $\alpha \neq 0$, then $\beta\left(X \times W\left(\omega_{\alpha}\right)\right)=X \times W\left(\omega_{\alpha}+1\right)$.

Proof. See ([10], page 92).

THEOREM 4.2 ([1], page 89). $X \subseteq Y \subseteq \beta X$, then $\beta Y=\beta X$.

LEMmA 4.3. For $\alpha Y \in K(Y)$, there exists $X$ such that $Y=\beta X \backslash X$ and $C l_{\beta X}(Y)=\alpha Y$.

Proof. Let $\lambda \neq 0$ be choosen, so that $|\alpha Y|<\boldsymbol{\aleph}_{2}$. By Theorem 
4.1, we have $\beta\left(\alpha Y \times W\left(\omega_{\lambda}\right)\right)=\alpha Y \times W\left(\omega_{\lambda}+1\right)$. Let $X=\beta(\alpha Y \times$ $\left.W\left(\omega_{\lambda}\right)\right) \backslash\left(Y \times\left\{\omega_{\lambda}\right\}\right)$, then $\alpha Y \times W\left(\omega_{\lambda}\right) \subseteq X \leqq \beta\left(\alpha Y \times W\left(\omega_{\lambda}\right)\right)$ and hence $\beta X=\beta\left(\alpha Y \times W\left(\omega_{\lambda}\right)\right)=\alpha Y \times W\left(\omega_{\lambda}+1\right)$. Since $\alpha Y \times\left\{\omega_{\lambda}\right\}$ is compact and contains $Y \times\left\{\omega_{\lambda}\right\}=Y$ as a dense subspace, $X$ is the space desired.

Corollary 4.4. For any space $Y$ there is an $X$ such that $\beta X \backslash X=Y$ and $Y$ is $C^{*}$-embedded in $X$.

THEOREM 4.5. ${ }^{2}$ Given any two spaces $X$ and $Y$, there is an $\alpha X \in K(X)$ such that $Y$ is homeomorphic to $C l_{\alpha X}(\alpha X \backslash X)$ iff there is a continuous map $h$ from $C l_{\beta X}(\beta X \backslash X)$ onto $Y$ such that $h(\beta X \backslash X) \leqq$ $Y \backslash h(R(X))$ and $h$ is one-to-one on $R(X)$, where $R(X)$ is the set of points at which $X$ is not locally compact.

EXAMPLE 4.6. (1) Let $\omega N$ be the one-point compactification of $N$. Then there exists $X$ such that $\beta X \backslash X=N$ and $C l_{\beta X}(N)=\omega N$. There exists a sequence, namely $N$, which converges to $\left(\omega, \omega_{1}\right) \in X$. Thus $K(X)$ is not a lattice by 2.8 .

In the above example, $\beta X \backslash X$ is realcompact and a $P$-space but not $C^{*}$-embedded in $\beta X$.

EXAMPLE 4.7. (2) If $Y=W\left(\omega_{1}\right)$, then $\beta Y=W\left(\omega_{1}+1\right)$. Let $X=(\beta Y \times \beta Y) \backslash\left(Y \times\left\{\omega_{1}\right\}\right)$, then $\beta X \backslash X=Y$. Let $\mathscr{D}$ be the collection of subsets of $\beta X$ of the form $\left\{\left(\lambda+2 j, \omega_{1}\right),\left(\lambda+2 j+1, \omega_{1}\right)\right\}$ for $\lambda$ a limit ordinal, $j=0,1,2, \cdots$, and all other singletons. Then $\mathscr{D}$ is a decomposition space of $X$. Let $P: X \rightarrow \mathscr{D}$ be the quotient map, then $\mathscr{D}$ can be considered as the quotient space of $X$ induced by $P$. Clearly $P\left(C l_{\beta_{X}} Y\right)$ is compact Hausdorff. By 4.5 we have $\mathscr{D}=$ $\alpha_{1} X \in K(X)$. Similarly, let $\mathscr{D}^{\prime}$ be the collection of subsets of $\beta X$ of the form $\left\{\left(\alpha+2 j-1, \omega_{1}\right),\left(\alpha+2 j, \omega_{1}\right)\right\}$ for $\alpha$ a limit ordinal, $j=1,2, \cdots$, and all other singletons, then $\mathscr{D}^{\prime}=\alpha_{2} X \in K(X)$. If $\alpha X \in K(X)$ and $\alpha X \leqq \alpha_{1} X, \alpha_{2} X$, then the following diagram commutes:



Thus, if $f_{\alpha}((\lambda, \omega))=y$, for some $\lambda$ a limit ordinal then $f((\lambda+j$,

\footnotetext{
2 This theorem is a modified version of theorem due to Rayburn [5].
} 
$\left.\left.\omega_{1}\right)\right)=y$ for all $j \in N$. Therefore, $f_{\alpha}\left(W \times\left\{\omega_{1}\right\}\right)=y=f_{\alpha}\left(\left(\omega_{1}, \omega_{1}\right)\right)$, which is a contradiction since $f_{\alpha}(\beta X \backslash X) \leqq f_{\alpha}(\beta X) \backslash f_{\alpha}(X)$. Hence $K(X)$ is not a lattice.

In this example, the subspace $\beta X \backslash X$ is $C^{*}$-embedded but not realcompact nor a $P$-space. We also claim that $\alpha X \backslash X$ is not a $P$ space for any $\alpha X \in K(X)$. For if $\alpha X \backslash X$ is a $P$-space, then $\alpha X \backslash X$ contains a $C$-embedded copy of $N$, which implies $Y$ contains a $C$ embedded copy of $N$. But this is not possible since $Y$ is pseudocompuct.

EXAMPLE 4.9. (3) Let $Y$ be the subspace of $W\left(\omega_{2}\right)$ obtained by deleting all nonisolated points having a countable base, then $Y$ is a $P$-space that is not realcompact ([1], page 138).

Let $X$ be chosen so that $\beta X \backslash X=Y$ ahd $Y C^{*}$-embedded in $\beta X$, then $K(X)$ is a lattice by Theorem $3.9, \beta X \backslash X$ is not realcompact.

ExAmple 4.3. (4) Let $Q$ be the set of rationals. Choose $X$ so that $\beta X \backslash X=Q$ and $Q$ is $C^{*}$-embedded in $\beta X$. Since $Q$ is realcompact, $K(X)$ is a lattice. We claim that $\alpha X \backslash X$ is not a $P$-space for any $\alpha X \in K(X)$. For if $\alpha X \backslash X$ is a $P$-space, then $f_{\alpha}\left(\mathscr{C l}_{\alpha}\right)$ contains a $C$-embedded copy of $N$ which contradicts Lemma 3.6.

Example 4.10. (5) $E=\{2 n \mid n \in N\}$ and $0=\{2 n+1 \mid n \in N\}$. Then $N=E \cup 0$ and $E \cap 0=\phi$. Define $t: N \rightarrow N$ by $t(2 n)=2 n+1$ and $t(2 n+1) 2 n, n \in N$. Thus, $t(E)=0$ and $t(0)=E$. For each $p \in \beta N \backslash N$, there exists a unique free ultrafilter $\mathscr{U}_{p}$ on $N$ such that $\mathscr{U}_{p} \rightarrow p$. Let $\overline{\mathscr{C}}=\left\{\mathscr{U}_{p}\right\}_{p \in \beta N / N}$. It is clear that $\overline{\mathscr{C}}$ is exactly the set of free ultrafilters on $N$. Define $\overline{\mathscr{U}}_{E}=\left\{\mathscr{U}_{p} \in \overline{\mathscr{U}}_{\mid} \mid E \in \mathscr{U}_{p}\right\}$ and $\overline{\mathscr{U}}_{0}=$ $\left\{\mathscr{U}_{p} \in \overline{\mathscr{U}} \mid 0 \in \mathscr{U}_{p}\right\}$. Obviously, $\mathscr{U}_{E}$ and $\mathscr{U}_{0}$ form a partition of $\overline{\mathscr{U}}$. If $\overline{\mathscr{U}}_{p} \in \mathscr{U}_{E}$, then $t\left(\mathscr{U}_{p}\right)$ the ultrafilter generated by $\left\{t(u) \mid u \in \mathscr{Q}_{p}\right\}$ is identical to $\left\{t(u) \mid u \in \mathscr{Z}_{p}\right\}$, furthermore, $t\left(\mathscr{U}_{p}\right) \in \overline{\mathscr{U}}_{0}$. Similarly, $t\left(\mathscr{U}_{p}\right) \in \overline{\mathscr{U}}_{E}$ if $\mathscr{U}_{p} \in \overline{\mathscr{U}}_{0}$. Thus, $t$ induces a one-to-one correspondence


$\overline{\mathscr{U}}$, therefore the partition $\overline{\mathscr{U}}=\overline{\mathscr{U}}_{E} \cup \overline{\mathscr{U}}_{0}, \overline{\mathscr{U}}_{E} \cap \overline{\mathscr{U}}_{0}=\phi$ induces a partition on $\beta \boldsymbol{N} \backslash \boldsymbol{N}$. The induced partition is $\beta \boldsymbol{N} \backslash \boldsymbol{N}=\left(C l_{\beta_{N}}(E) \backslash E\right) \cup$ $\left(C l_{\beta N}(0) \backslash 0\right)$ with $\left(C l_{\beta N}(E) \backslash E\right) \cap\left(C l_{\beta N}(0) \backslash 0\right)=\phi$. Define a relation $\sim$ on $\beta N$ as follows: $p_{1} \sim p_{2}$ if and only if $p_{1}=p_{2}$ or $t\left(\mathscr{C}_{p_{1}}\right)=\mathscr{U}_{p_{2}}$. Then $\sim$ is an equivalence relation on $\beta N$. Let $\mathscr{D}$ be the identification space $\beta N / \sim$ with the quotient map $P$. Clearly $\mathscr{D}$ is compact and $T_{1}$. We want to show $\mathscr{D}$ is Hausdorff. For $x \in P(N), P^{-1}(x)$ is a singleton in $N$, so $P^{-1}(x)$ is both open and closed in $\beta N$. It follows that $\{x\}$ is both open and closed in $\mathscr{D}$. Thus $x$ can be separated from any other point by open sets in $\mathscr{D}$. Let $p, q \in P(\beta \boldsymbol{N} \backslash \boldsymbol{N})$. Then 
$P^{-1}(p)=\left\{p_{1}, p_{2}\right\}$, and $P^{-1}(q)=\left\{q_{1}, q_{2}\right\}$ for $p_{1}, q_{1} \in C l_{\beta_{\mathbf{N}}}(E) \backslash E$ and $p_{2}, q_{2} \in$ $C l_{\beta N}(0) \backslash 0$. Let $u, v$ be open in $\beta N$ such that $u, v \leqq C l_{\beta N}(E), p_{1} \in u$, $q_{1} \in v$ and $u \cap v=\phi$. Let $\bar{t}$ be the extension of $t$ from $\beta N$ to $\beta N$. Obviously, $\bar{t}$ is a homeomorphism, so $\bar{t}(u)$ and $\bar{t}(v)$ are open in $\beta \boldsymbol{N}$, moreover $\bar{t}(u), \bar{t}(v) \subseteq C l_{\beta_{N}}(0)$ and $p_{2} \in \bar{t}(u), q_{2} \in \bar{t}(v)$. Let $G=P(u \cup$ $(\bar{t}(u))), H=P(v \cup(\bar{t}(v)))$. Clearly, $P^{-1}(G)=u \cup(\bar{t}(u))$ and $P^{-1}(H)=$ $v \cup(\bar{t}(v))$, so $G$ and $H$ are open in $\mathscr{D}$. Since $p \in G, q \in H, G \cap H=\phi$, so $p, q$ can be separated by open sets. Thus $\mathscr{D}$ is Hausdorff. Thus there is a $\gamma \boldsymbol{N} \in K(\boldsymbol{N})$ such that $\gamma \boldsymbol{N}=\mathscr{D}$.

Let $X$ be obtained as in Lemma 4.3 such that $\beta X \backslash X=N$ and $C l_{\beta X}(N)=\gamma N$. For $\alpha X \in K(X)$, we claim $\alpha X$ has the following properties.

(1) $\mathscr{S}_{1}^{\alpha}=\left\{F \in \mathscr{E}_{\alpha}|| F \mid \geqq 3\right\}$ is finite,

(2) $\mathscr{S}_{2}^{\alpha}=\left\{F \in \mathscr{E}_{\alpha}|| F \mid=2, F \subseteq E\right\}$ and

$\mathscr{S}_{3}^{\alpha}=\left\{F \in \mathscr{E}_{\alpha}|| F \mid=2, F \cong E\right\}$ are finite,

(3) Let $\mathscr{C}_{\alpha}=\left\{F \in \mathscr{E}_{\alpha}|| F \cap E|=| F \cap 0 \mid=1\right\}$, then $\mathscr{S}_{4}^{\alpha}=\left\{F \in \mathscr{C}_{\alpha} \mid F \neq\{2 n, 2 n+1\}\right.$ for any $\left.n \in N\right\}$ is finite.

Proof of (1). If $\mathscr{S}_{1}^{\alpha}$ is infinite, then $\mathscr{l}_{\alpha}$ contains three copies of $N$, say $\left\{A_{i}\right\}_{i=1}^{3}$, which are $C$-embedded in $N \subseteq \beta X$ such that $\left\{A_{i}\right\}_{i=1}^{3}$ is a section partition induced by $f_{\alpha}$. Clearly, $\left\{f_{\gamma}^{-1}\left(A_{i}\right)\right\}_{i=1}^{3}$ is a section partition induced by $g_{\alpha} \circ f_{\gamma}$ where $g_{\alpha}$ is the restriction of $f_{\alpha}$ to $C l_{\beta X}(N)=\gamma N$. Let $\left(a_{\lambda}^{(1)}\right)$ be an ultranet in $A_{1}$ and $a_{\lambda}^{(1)} \rightarrow a_{1} \in \beta N \backslash N$. Let $\left(a_{\lambda}^{(2)}\right) \subseteq A_{2},\left(a_{\lambda}^{(3)}\right) \subseteq A_{3}$ be ultranets induced by the section correspondences which are induced by $g_{\alpha} \circ f_{\gamma}$ on $\left(g_{\alpha} \circ f_{\gamma}\right)\left(A_{1}\right)$. Let $a_{\lambda}^{(2)} \rightarrow a_{2}$, $a_{\lambda}^{(3)} \rightarrow a_{3}$, where $a_{2}, a_{3} \in \beta N \backslash N$. Obviously $a_{1}, a_{2}, a_{3}$ are distinct. By the definition of $\gamma \boldsymbol{N}, \quad\left|f_{\gamma}\left(\left\{a_{i}\right\}_{i=1}^{3}\right)\right| \geqq 2 . \quad f_{\gamma \mid X}$ is one-to-one, so $\left|\left(g_{\alpha} \circ f_{\gamma}\right)\left(\left\{a_{i}\right\}_{i=1}^{3}\right)\right| \geqq 2$. This is not possible, since $\left(g_{\alpha} \circ f_{\gamma}\right)\left(a_{\lambda}^{(1)}\right)=$ $\left(g_{\alpha} \circ f_{\gamma}\right)\left(a_{\lambda}^{(2)}\right)=\left(g_{\alpha} \circ f_{\gamma}\right)\left(a_{\lambda}^{(3)}\right)$ for all $\lambda$ which implies $\left|\left(g_{\alpha} \circ f_{\gamma}\right)\left(\left\{a_{i}\right\}_{i=1}^{3}\right)\right|=1$. Thus (1) holds.

Proof of (2). It is sufficient to show $\mathscr{S}_{2}^{\alpha}$ cannot be infinite. Suppose $\mathscr{S}_{2}^{\alpha}$ is infinite, then $E$ contains two copies of $N$, say $A_{1}$ and $A_{2}$, which are $C$-embedded in $N=\beta X \backslash X$ such that $\left\{A_{1}, A_{2}\right\}$ is a section partition induced by $f_{\alpha}$. This is not possible, since no twopoints in $C l_{\beta N}(E)$ are equivalent with respect to $\sim$, and $f_{\gamma \mid X}$ is oneto-one. Thus (2) holds.

Proof of (3). If $\mathscr{S}_{4}^{\alpha}$ is infinite, then there exists $A=\left\{a_{n}\right\}_{n=0}^{\infty} \subseteq E$, $B=\left\{b_{n}\right\}_{n=0}^{\infty} \subseteq 0$ such that $\{A, B\}$ is a section partition induced by $f_{\alpha}$, $\left\{a_{n}, b_{n}\right\} \in \mathscr{S}_{4}^{\alpha}$ for $n \in N$, and $t(A) \cap B=\phi$. Let $a \in C l_{\beta N}$, then $t\left(\mathscr{U}_{a}\right) \rightarrow$ $\bar{t}(a) \notin C l_{\beta N}(B)$, since $B \notin t\left(\mathscr{U}_{a}\right)$. Let $\left(a_{\lambda}\right)$ be the ultranet in $A$ based on $A \cap \mathscr{C}_{a}$ such that $a_{\lambda} \rightarrow a$. Let $\left(b_{\lambda}\right)$ be the ultranet in $B$ induced by the map $a_{n} \rightarrow b_{n}$. Then $b_{\lambda} \rightarrow b \in C l_{\beta N}(B) N . \quad a$ and $b$ are not 
equivalent with respect to $\sim$. Thus $f_{\gamma}(a) \neq f_{\gamma}(b)$. However, $\left(g_{\alpha} \circ f_{\alpha}\right)(a)=$ $\left(g_{\alpha} \circ f_{\tau}\right)(b)$. This is a contradiction. Hence (3) holds.

Let $\mathscr{S}_{\alpha}=\left\{F \in \mathscr{C}_{\alpha} \mid F=\{2 n, 2 n+1\}\right.$ for some $\left.n \in N\right\}, G_{\alpha}=\{x \in$ $\mathscr{L}_{\alpha} \mid x \in F$ for some $\left.F \in \mathscr{S}_{\alpha}\right\}$. Let $K_{\alpha}=\left\{x \in \mathscr{L}_{\alpha} \mid x \in \bigcup_{i=1}^{4} \mathscr{S}_{i}^{\alpha}\right\}$. Then $\mathscr{H}_{\alpha}=G_{\alpha_{i}} \cup K_{\alpha}$.

Using these notations, for $\alpha_{1} X, \alpha_{2} X \in K(X)$, we write $\mathscr{C}_{\alpha_{i}}=$ $G_{\alpha_{i}} \cup K_{\alpha_{i}}, i=1,2$. We want to show that $\alpha_{1} X$ and $\alpha_{2} X$ have a lower bound in $K(X)$. Let $\tau X$ be obtained by idetifying subsets of $\beta X$ of the form $\{2 n, 2 n+1\}$ to a point for each $n \in N$. It is clear that $\tau X \in K(X)$. Let $K=f_{\tau}\left(K_{\alpha_{1}} \cup K_{\alpha_{2}}\right)$. Obtain $\alpha X$ by identifying $K$ to a point, then $\alpha X \in K(X)$. Each set in $\mathscr{F}\left(\alpha_{i} X\right)$ is a subset of a set in $\mathscr{F}(\alpha X)$, thus $K(X)$ is a lattice by Theorem 2.2 .

This example shows that the condition $C l_{\beta X}\left(\mathscr{C}_{\alpha}\right) \subseteq \beta X \backslash X$ for every $\alpha X \in K(X)$ in Lemma 3.3 is not necessary for $K(X)$ to be a lattice.

\section{REFERENCES}

1. L. Gillman and M. Jerison, Rings of Continuous Functions, Van Nostrand, (1960), New York.

2. M. Henriksen and J. R. Isbell, Some properties of compactifications, Duke Math. J., 25 (1957), 83-105.

3. R. G. Lubben, Concerning the decomposition and amalgamation of points, uppersemi-continuous collections, and topological extensions, Trans. Amer. Math. Soc., 49 (1941), 410-466.

4. K. D. Magill, The lattice of compactifications of a locally compact space, Proc. London Math. Soc., 18 (1968), 231-244.

5. M. C. Rayburn, On Hausdorff Compactifications, Pacific J. Math., 44 (1973), 707-714.

6. T. Shirota, On systems of structures of a completely regular space, Osaka Math.

J., 2 (1950), 131-143.

7. Yusuf Unlü, Lattices of Compactifications of Tychonoff Spaces, Thesis, (1976), University of Kansas.

8. J. E. Vaughan, Spaces of countable type and point countable type, Trans. Amer. Math. Soc., 151 (1970), 341-351.

9. Ju. Visliseni and Ju. Fleksmoier, The power and the structure of the lattice of all compact extensions of a completely regular space, Soviet Math., 6 (1965), 1423-1425.

10. R. C. Walker, The Stone-Čech Compactification, Springer-Verlag, (1974), New York, Heidelberg, Berlin.

11. S. Willard, General Topology, Addison-Wesley, (1970), Reading, Massachusetts.

Received April 29, 1977 and in revised form October 14, 1977. This paper is based on my doctoral thesis submitted to North Carolina State University at Releigh under the direction of Richard E. Chandler to whom I wish to express my sincere appreciation for his guidance and encouragement.

North Carolina State University

RALEIGH, NC 27607 



\title{
PACIFIC JOURNAL OF MATHEMATICS
}

\section{EDITORS}

RICHARD ARENS (Managing Editor)

University of California

Los Angeles, CA 90024

Charles W. Curtis

University of Oregon

Eugene, OR 97403

C. C. MOORE

University of California

Berkeley, CA 94720
J. DUGUNDJI

Department of Mathematics

University of Southern California

Los Angeles, CA 90007

R. Finn and J. Milgram

Stanford University

Stanford, CA 94305

\section{ASSOCIATE EDITORS}
E. F. BECKENBACH
B. H. Neumann
F. WOLF
K. YosHidA

\section{SUPPORTING INSTITUTIONS}

\author{
UNIVERSITY OF BRITISH COLUMBIA \\ CALIFORNIA INSTITUTE OF TECHNOLOGY \\ UNIVERSITY OF CALIFORNIA \\ MONTANA STATE UNIVERSITY \\ UNIVERSITY OF NEVADA, RENO \\ NEW MEXICO STATE UNIVERSITY \\ OREGON STATE UNIVERSITY \\ UNIVERSITY OF OREGON
}

\author{
UNIVERSITY OF SOUTHERN CALIFORNIA \\ STANFORD UNIVERSITY \\ UNIVERSITY OF HAWAII \\ UNIVERSITY OF TOKYO \\ UNIVERSITY OF UTAH \\ WASHINGTON STATE UNIVERSITY \\ UNIVERSITY OF WASHINGTON
}

The Supporting Institutions listed above contribute to the cost of publication of this Journal, but they are not owners or publishers and have no responsibility for its content or policies.

Mathematical papers intended for publication in the Pacific Journal of Mathematics should be in typed form or offset-reproduced, (not dittoed), double spaced with large margins. Please do not use built up fractions in the text of the manuscript. However, you may use them in the displayed equations. Underline Greek letters in red, German in green, and script in blue. The first paragraph or two must be capable of being used separately as a synopsis of the entire paper. Items of the bibliography should not be cited there unless absolutely necessary, in which case they must be identified by author and journal, rather than by item number. Manuscripts, in triplicate, may be sent to any one of the editors. Please classify according to the scheme of Math. Reviews, Index to Vol. 39. All other communications should be addressed to the managing editor, or Elaine Barth, University of California, Los Angeles, California, 90024.

50 reprints to each author are provided free for each article, only if page charges have been substantially paid. Additional copies may be obtained at cost in multiples of 50 .

The Pacific Journal of Mathematics is issued monthly as of January 1966. Regular subscription rate: $\$ 72.00$ a year (6 Vols., 12 issues). Special rate: $\$ 36.00$ a year to individual members of supporting institutions.

Subscriptions, orders for numbers issued in the last three calendar years, and changes of address should be sent to Pacific Journal of Mathematics, P.O. Box 969, Carmel Valley, CA 93924, U.S.A. Older back numbers obtainable from Kraus Periodicals Co., Route 100, Millwood, NY 10546.

PUBLISHED BY PACIFIC JOURNAL OF MATHEMATICS, A NON-PROFIT CORPORATION

Printed at Kokusai Bunken Insatsusha (International Academic Printing Co., Ltd.). 8-8, 3-chome, Takadanobaba, Shinjuku-ku, Tokyo 160, Japan.

Copyright (C) 1978 by Pacific Journal of Mathematics Manufactured and first issued in Japan 


\section{Pacific Journal of Mathematics}

Vol. 77, No. $2 \quad$ February, 1978

Graham Donald Allen, Duals of Lorentz spaces ................... 287

Gert Einar Torsten Almkvist, The number of nonfree components in the decomposition of symmetric powers in characteristic p .......... 293

John J. Buoni and Bhushan L. Wadhwa, On joint numerical ranges ...... 303

Joseph Eugene Collison, Central moments for arithmetic functions . . . . . . 307

Michael Walter Davis, Smooth G-manifolds as collections of fiber

bundles ........................................ 315

Michael E. Detlefsen, Symmetric sublattices of a Noether lattice......... 365

David Downing, Surjectivity results for $\phi$-accretive set-valued

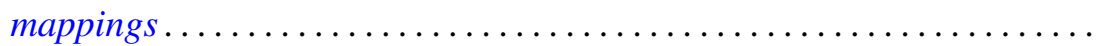

David Allyn Drake and Dieter Jungnickel, Klingenberg structures and partial designs. II. Regularity and uniformity ................. 389

Edward George Effros and Jonathan Rosenberg, $C^{*}$-algebras with approximately inner flip .......................... 417

Burton I. Fein, Minimal splitting fields for group representations. II. . . . . 445

Benjamin Rigler Halpern, A general coincidence theory ............. 451

Masamitsu Mori, A vanishing theorem for the mod $p$ Massey-Peterson spectral sequence ................................ 473

John C. Oxtoby and Vidhu S. Prasad, Homeomorphic measures in the

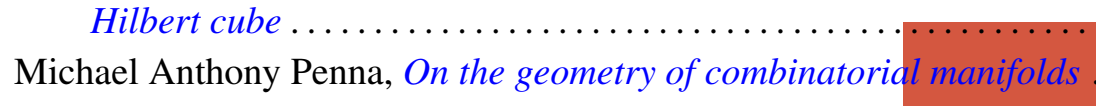

Robert Ralph Phelps, Gaussian null sets and differentiability of Lipschitz map on Banach spaces........................

Herbert Silverman, Evelyn Marie Silvia and D. N. Telage, Locally univalent functions and coefficient distortions...

Donald Curtis Taylor, The strong bidual of $\Gamma(K)$

Willie Taylor, On the oscillatory and asymptotic behavior of solutions of fifth order selfadjoint differential equations ...........

Fu-Chien Tzung, Sufficient conditions for the set of Hausdorff compactifications to be a lattice. 